\title{
PROPENSÃO À COLABORAÇÃO DA INDÚSTRIA NO CEARÁ: UMA ANÁLISE ENTRE A OFERTA E A DEMANDA DE TECNOLOGIAS
}

\section{PROPENSION TO INDUSTRY COLLABORATION IN CEARÁ: AN ANALYSIS BETWEEN THE SUPPLY AND DEMAND OF TECHNOLOGIES}

\author{
Brenno Buarque \\ Universidade Estadual do Ceará - UECE \\ brennobuarquework@gmail.com
}

Michelle do Carmo Sobreira

Universidade Estadual do Ceará -UECE

$\underline{\text { michellesobreira@gmail.com }}$

Samuel Façanha Câmara

Universidade Estadual do Ceará - UECE sfcamara2000@gmail.com

Elias Pereira Lopes Junior Universidade Federal do Cariri - UFCA - Ceará eliasjunior08@gmail.com

José Iran Batista de Melo Filho Universidade Estadual do Ceará - UECE irandemelo.idm@gmail.com

Submissão: $08 / 08 / 2020$

Aprovação: 28/10/2020

Agradecimento: Os autores expressam o agradecimento à FIEC, SESI/SENAI DO CEARÁ pelo apoio à pesquisa.

\section{RESUMO}

O objetivo da pesquisa foi identificar a propensão para colaboração entre ofertantes e demandantes de tecnologia na Indústria 4.0 do Ceará. Para isso, foi realizada uma survey aplicada aos ofertantes de tecnologia, que buscou compreender a tecnologia da instituição, bem como a sua aplicação e a sua proposta de valor para o setor industrial. As questões objetivas visavam medir o nível de maturidade da tecnologia, e também levantar a disposição em colaborar com uma empresa interessada em investir na tecnologia para desenvolvê-la. No caso da demanda, buscou-se levantar de um a dois problemas ou oportunidades existentes na empresa que pudessem ser solucionados por meio do desenvolvimento de uma tecnologia, os quais o respondente deveria descrever e apontar o nível de gravidade, urgência e tendência dos problemas ou oportunidades. Foi possível identificar que a maioria dos ofertantes já possuem produto pronto para o mercado, enquanto os demandantes têm maior necessidade justamente por esses produtos prontos. Seguido dos produtos acabados, a pesquisa demonstrou que as indústrias também possuem muito interesse em colaborar no 
desenvolvimento de tecnologias que ainda estão em fase de pesquisa, retratando que parte dos seus problemas não serão resolvidos com um produto padrão e deve ser individualizado.

Palavras chaves: Technology-push; Demanda-pull; Oferta Tecnológica

\begin{abstract}
The objective of the research was to identify the propensity for collaboration between providers and demanders of technology in Industry 4.0 of Ceará. For this, a survey was carried out on technology providers that sought to understand the institution's technology, as well as its application and its value proposition for the industrial sector. The objective questions aimed to measure the level of maturity of the technology, and also to raise the willingness to collaborate with a company interested in investing in the technology to develop it. In the case of demand, we sought to raise one to two problems or opportunities existing in the company that could be solved through the development of a technology, which the respondent should describe and point out the level of severity, urgency and tendency of the problems or opportunities. It was possible to identify that most of the offerers already have a product ready for the market, while the claimants have a greater need precisely for these ready products. Followed by the finished products, the research showed that the industries are also very interested in collaborating in the development of technologies that are still in the research phase, portraying that part of their problems will not be solved with a standard product and must be individualized.
\end{abstract}

Keywords: Technology-push; Demanda-pull; Technological offer

\title{
1 INTRODUÇÃO
}

A inovação tecnológica é fundamental para o desenvolvimento econômico. Ela possui impacto na economia de um país e é um fator essencial para a competitividade de uma nação. Não é sem motivo que os países desenvolvidos investiram fortemente em ciência e tecnologia no decorrer de sua história (KIM, 1997). Governo e empresas investem fortemente em inovação com o intuito de gerar vantagem competitiva para a indústria (IRELAND; WEBB, 2007; KETCHEN JR; IRELAND; SNOW, 2007; MAZZUCATO, 2014).

No que diz respeito às empresas, estas precisam estar constantemente inovando em processos e produtos para se manterem competitivas (VASCONCELOS; CYRINO, 2000). Essa necessidade se manifesta fortemente no setor industrial, especialmente em setores no qual a inovação tecnológica é a base para vantagem competitiva. No Brasil, a indústria teve forte crescimento entre 1930 e 1980, estimulado por políticas bem definidas. No entanto, nas últimas décadas, o país estagnou no desenvolvimento industrial, e recentemente têm adotado iniciativas para que possa se manter competitivo frente à nova onda de desenvolvimento tecnológico industrial (SILVA; LAPLANE, 1994; LOURAL, 2016).

É sabido que a baixa produtividade está na raiz das dificuldades da economia brasileira, e na sua capacidade de sustentar longos ciclos de crescimento e de geração de empregos de qualidade (ARBIX; MIRANDA, 2015), muito em parte pela deficiência da cultura de inovação nas organizações. Assim, faz-se necessário um ambiente econômico que seja favorável e que estimule a inovação entre os diversos atores do setor industrial. Esse ambiente necessita surgir de maneira bottom-up, criando-se um ecossistema de inovação a partir do ambiente local da cidade e da região. Assim, não é necessário esperar por soluções top-down, que surjam por meio de leis ou políticas macroeconômicas. 
Dessa forma, é importante que seja construído um ecossistema de inovação regional (BRESCHI; MALERBA, 2005). Para isso, é necessário que os diversos atores desse ecossistema estejam alinhados com as iniciativas que ocorrem neste ambiente. Os gestores industriais precisam conhecer as iniciativas de inovação locais voltadas para seu setor. Para isso, é preciso que exista um contato entre a indústria e as instituições que desenvolvem iniciativas de inovação tecnológica. Esse contato pode se dar por meio de um pesquisador que possua uma tecnologia que supra uma demanda específica da indústria, ou também como por um gestor de uma start-up que possui um produto voltado para o setor industrial. Para além disso, é importante que estes atores estejam dispostos a colaborar com um mesmo propósito em comum, de gerar aprendizagem entre esses atores e inovação para suas instituições (BALESTRIN; VERSCHOORE, 2010).

Nessa direção, existem diversas iniciativas no Brasil no intuito de gerar conexão entre o setor industrial e as Instituições de Ciência e Tecnologia, bem como com startups e empresas de base tecnológica (FREIRE; MARUYAMA; POLLI, 2017). Recentemente surgiram iniciativas que procuram realizar essa conexão com foco em tecnologias da Indústria 4.0 (VERMULM, 2018), com o intuito de desenvolver as tecnologias desta nova revolução industrial no território brasileiro.

Devido ao recente acontecimento desse fenômeno da Indústria 4.0, há poucos estudos que visem compreender como se ocorre a disponibilidade de ofertas tecnológicas e de demandas industriais locais. Tampouco há estudos que relacionem estas informações com a propensão à colaboração de ambas as partes - setor industrial e ofertantes de tecnologia, gestores de startups e pesquisadores de Instituição Científica e Tecnológica (ICT). Assim, este artigo busca contribuir com esta lacuna de estudos, ao relacionar demandas e ofertas tecnológicas da Indústria 4.0 com a propensão à colaboração. A questão de pesquisa que guia este trabalho é: qual a propensão para colaboração entre ofertantes e demandantes de tecnologia na Indústria 4.0 do Ceará?

Além desta introdução, o artigo se divide em mais quatro seções. A primeira seção trata do arcabouço teórico que promove o entendimento sobre o objeto estudado, a segunda seção descreve o percurso metodológico da pesquisa, a terceira seção aborda a análise dos resultados e a quarta seção expõe as conclusões do estudo assim como sua limitação e sugestão de trabalhos futuros.

\section{O PAPEL DA INDÚSTRIA PARA O DESENVOLVIMENTO TECNOLÓGICO}

Historicamente, a evolução da indústria tem sido uma das principais forças motrizes para o desenvolvimento da sociedade e os avanços tecnológicos têm impulsionado aumentos na produtividade industrial desde o início da Revolução Industrial. Como exemplos desses avanços, tem-se as fábricas movidas a vapor (século XVIII), a produção em massa por meio da eletrificação (século XIX) e a automatização da indústria (década de 1970). Contudo, em comparação com outros segmentos como comunicação móvel e comércio eletrônico, nas últimas décadas, os avanços tecnológicos industriais foram apenas incrementais e, atualmente, a quarta revolução industrial (Indústria 4.0) está em andamento (FIGURA 1), com as características da produção de sistemas físicos cibernéticos com base em dados heterogêneos e integração de conhecimento (LUKAC, 2015). 


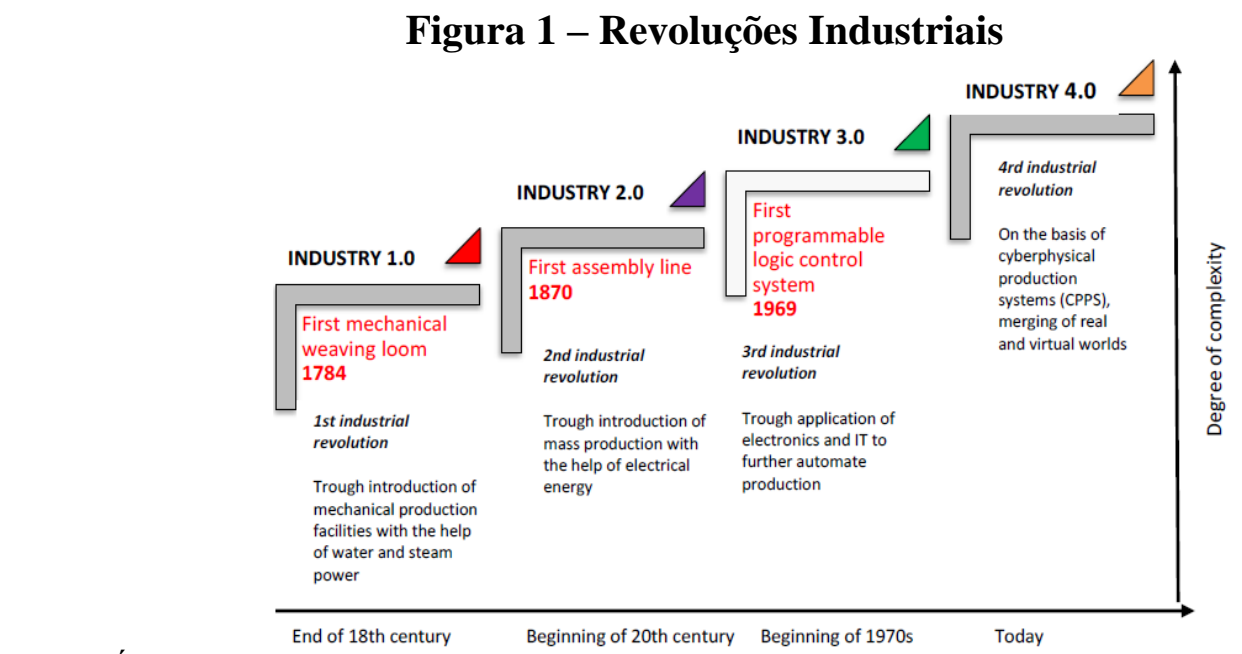

Fonte: Ślusarczyk (2018)

Nessa nova tecnologia industrial digital, conhecida como Indústria 4.0, em que sensores, máquinas, peças de trabalho e sistemas de Tecnologia da Informação e Comunicação (TIC) podem interagir entre si, utilizam-se de protocolos padrão baseados na internet para analisar dados, prever falhas, atualizar suas configurações e promover uma adaptação às mudanças (LASI, 2014; VAIDYA; AMBAD; BHOSLE, 2018).

Com o advento do setor 4.0 é possível reunir e analisar dados entre máquinas, tornando os processos mais rápidos, mais flexíveis e mais eficientes na produção de mercadorias com maior qualidade e com custos reduzidos (THAMES; SCHAEFER, 2016). Outros benefícios da Indústria 4.0 são a digitalização, a otimização, a customização da produção e o oferecimento de serviços e negócios com maior valor agregado (POSADA et al., 2015; ROBLEK; MEŠKO; KRAPEŽ, 2016; THAMES; SCHAEFER, 2016).

$\mathrm{Na}$ literatura que trata de Gestão Tecnológica, existem dois modelos como caminho para gerar inovação e desenvolvimento tecnológico. Essas duas abordagens clássicas dizem respeito à oferta e a demanda tecnológica, ou seja, se essa tecnologia está partindo de uma oferta de uma instituição que fomenta a pesquisa, desenvolvimento e inovação, ou se surge a partir de uma demanda de um grupo de consumidores (CHOI, 2017).

Segundo Campos (2006), essas abordagens consideram o conhecimento científico ou a demanda do mercado como determinantes nesse processo. O modelo que é impulsionado pelo conhecimento científico, caracterizado como technology-push, segue o modelo linear da inovação, no qual uma tecnologia surge a partir da pesquisa, do desenvolvimento e da posterior inovação no mercado. Do outro lado, o modelo do demanda-pull ou Market Pull enfatiza a inovação como advinda a partir de demandas do mercado. Assim, esses modelos são utilizados para explicar as origens da inovação tecnológica (SETHI; AHUJA; SINGLA, 2018).

O technology-push é caracterizado, no setor industrial, por empresas que investem em pesquisa e desenvolvimento e geram novos produtos a partir disso, seus objetivos independentes são motivados pela ciência e estimulados pela tecnologia (SINGLA; AHUJA; SETHI, 2018).

Maçaneiro e Cunha (2012) apontam um modelo no qual a tecnologia e as demandas se apresentam antes da ciência, substituindo a pesquisa por descoberta tecnológica e/ou demanda de mercado. Nesse novo modelo, o science-push seria transferido para dentro do market-pull.

A estrutura produtiva pode ser considerada um fator relevante na determinação do crescimento econômico de um país (VIEIRA; AVELLAR; VERÍSSIMO, 2014). Em economias em desenvolvimento, os governos precisam fornecer proteção e subsídios substanciais a empresas para compensar as falhas de mercado (LIN; CHANG, 2009). 
Vieira, Avellar e Veríssimo (2014) e Singla, Ahuja e Sethi (2018) advogam que a indústria impacta na economia, no emprego e no desenvolvimento sustentável colaborando com os negócios e a sociedade em geral. Além disso, é importante para o crescimento econômico dos países de economias emergentes e em desenvolvimento, sugerindo que essas economias têm benefícios adicionais em termos de crescimento de longo prazo ao adotarem políticas que estimulem a participação do setor industrial. Mais recentemente, o setor industrial têm utilizado de diferentes meios de transferência tecnológica para alavancar seu desempenho e aumentar sua competitividade.

\title{
3 NECESSIDADES TECNOLÓGICAS DA INDÚSTRIA CEARENSE
}

$\mathrm{O}$ fato de existir um grande número de tecnologias torna as empresas incapazes de desenvolver todas as tecnologias que são necessárias para a manutenção de sua competitividade frente ao mercado. Portanto, a transferência de tecnologia é uma alternativa eficaz para que as empresas possam adquirir tecnologias necessárias para o seu crescimento (BRAGA JR; PIO; ANTUNES, 2009).

\begin{abstract}
O objetivo desta comercialização é gerar um impacto econômico. A transferência tecnológica pode ser utilizada como uma ferramenta, na tentativa de duas organizações buscarem um objetivo comum, gerando como resultado a plena satisfação das partes. Em um mercado competitivo e altamente veloz nas mudanças de produtos e serviços, a transferência de tecnologia se tornou parte efetiva das estratégias tecnológicas e corporativas das empresas. O desenvolvimento ou compra de uma tecnologia devem ser vistos como uma ação da estratégia tecnológica corporativa de uma empresa (BRAGA JR; PIO; ANTUNES, 2009, p.1).
\end{abstract}

Para Chiarello (2009), o setor produtivo de conhecimento no Brasil é praticamente representado por instituições públicas, enquanto que o setor usuário, aquele que internaliza o conhecimento e gera bens e serviços, é geralmente privado. Contudo, existe um problema relacionado ao baixo grau de apropriação do conhecimento para promover a inovação e é necessário um esforço conjunto para aumentar a conexão entre esses dois setores. Um problema corriqueiro é o simples desconhecimento das demandas tecnológicas por parte das empresas e das ofertas tecnológicas por parte das instituições de ciência e tecnologia.

Conforme Garcia, Rapini e Cário (2018), as relações entre universidades e empresas no Brasil não apenas existem, mas são relativamente intensas. Contudo, essa interação não tem foco em inovações de maior alcance. As demandas tecnológicas oriundas das empresas são mais restritas a características estruturais da dinâmica tecnológica periférica.

Entretanto, existem algumas ações que visam promover a conexão entre empresas e instituições de ciência e tecnologia. A Rede de Tecnologia (RETEC), articulada pelo IEL, teve início pelo Estado da Bahia e foi expandida para mais cinco unidades da federação: Ceará, Minas Gerais, Amazonas, Paraná e Distrito Federal. A RETEC capta as demandas oriundas das indústrias, empresas e instituições acadêmicas e, de outro lado, organiza uma lista de especialistas, instituições e empresas capazes de responder a essas demandas (VELOSO FILHO; NOGUEIRA, 2016).

Outra ação que vem dando certo há muito tempo no estado do Ceará é a Fundação Núcleo de Tecnologia Industrial do Ceará - NUTEC. A fundação atua desde 1978, viabilizando soluções tecnológicas para o desenvolvimento industrial sustentável em benefício da sociedade. Para tanto, o NUTEC conta com diversos Laboratórios, Projetos de Extensão, Incubadora de Empresas, Núcleo de Inovação Tecnológica e Biblioteca Especializada (NUTEC, 2020).

Recentemente, no estado do Ceará, foi lançado o Centro de Excelência em Inovação (CEI) do Sistema da Federação das Indústrias do Estado do Ceará (FIEC) na qual, por meio de suas instituições tais como, Serviço Social da Indústria (SESI), Serviço Nacional de 
Aprendizagem Industrial (SENAI) e o Instituto Euvaldo Lodi (IEL), apoia empresas na resolução de diversos desafios, que vão desde a redução de riscos até a estruturação e captação de recursos para projetos inovadores (FIEC, 2020a).

Outra ação da FIEC é o Observatório da Indústria, que iniciou suas atividades oficialmente em outubro de 2018 e é considerado um como um marco na inteligência industrial do Ceará. Sua principal função é construir e articular conhecimento com foco em inteligência competitiva, disponibilizando informações socioeconômicas para a tomada de decisões estratégicas que poderá ser acessada pelas indústrias cearenses, investidores, governo e academia (FIEC, 2020b).

Em agosto de 2017, foi firmada uma parceria entre o governo do Estado do Ceará e a Fiocruz para desenvolver o Polo Industrial e Tecnológico da Saúde. Com isso, o Governo planeja levar indústrias de referência no Brasil e no Exterior para ocupar o espaço e solidificar a produção para o setor. Inicialmente, o foco será o estudo da biologia dos microorganismos, doenças e vacinas. As tecnologias desenvolvidas poderão, por exemplo, ser usadas na produção de uma nova vacina para febre amarela e do biofármaco alfataliglicerase, para tratamento da doença de Gaucher (GOVERNO DO CEARÁ, 2017).

Outro projeto que vem se destacando na tentativa de promoção da interação entre empresas e universidades é a Rede de Núcleos de Inovação do Ceará (REDENIT-CE). Criada em janeiro de 2010, a REDENIT-CE tem como objetivos identificar e gerar estratégias para que as pesquisas desenvolvidas pelas ICT se transformem em inovação e negócios, visando à proteção do conhecimento e à transferência da inovação tecnológica para o mercado. Contribui, dessa maneira, com o desenvolvimento tecnológico do Estado do Ceará, pelo apoio à estruturação dos Núcleos de Inovação Tecnológica (NIT) de cada ICT envolvida (REDENIT-CE, 2020).

A FIEC tem se esforçado para estimular e induzir a cultura da inovação nas indústrias cearenses. Muitas empresas querem e sabem que precisam avançar nesse tema, mas, não sabem por onde começar ou como seguir adiante. Nesse sentido, a FIEC desenvolveu o projeto Bússola da Inovação, que tem a função de servir como guia nesse passo decisivo para o crescimento da empresa (BÚSSOLA DA INOVAÇÃO, 2016).

A Bússola da Inovação (2016) coletou informações de 544 empresas que possuem unidade produtiva no Estado do Ceará dos setores de Construção, Indústria de Transformação e de TIC. Os resultados mostram que a interação entre indústrias e universidades ou institutos de pesquisa na busca por fomentar a inovação ainda é muito baixa, $65 \%$ das indústrias não interagiram com as universidades. Por outro lado, o grau de interação das empresas é mais alto com fornecedores, interação de $56 \%$, entre moderada e muita alta, com os clientes e consumidores a interação fica na faixa dos $57 \%$, sendo também moderada e muita alta.

A inovação envolve diretamente a introdução de um novo produto ou a melhoria significativa dos já existentes. Assim, as empresas foram consultadas sobre as inovações que realizaram e, conforme o Gráfico 1, observou-se que as inovações estiveram, relativamente, mais relacionadas a produtos (49\% novos e $48 \%$ de melhoria nos existentes), processos produtivos (46\%) e práticas de gestão (43\%), e, em menor intensidade, as mudanças na comercialização (26\%), desenho/embalagem $(23 \%)$ ou na distribuição dos produtos (20\% melhoria e $15 \%$ novo processo). 


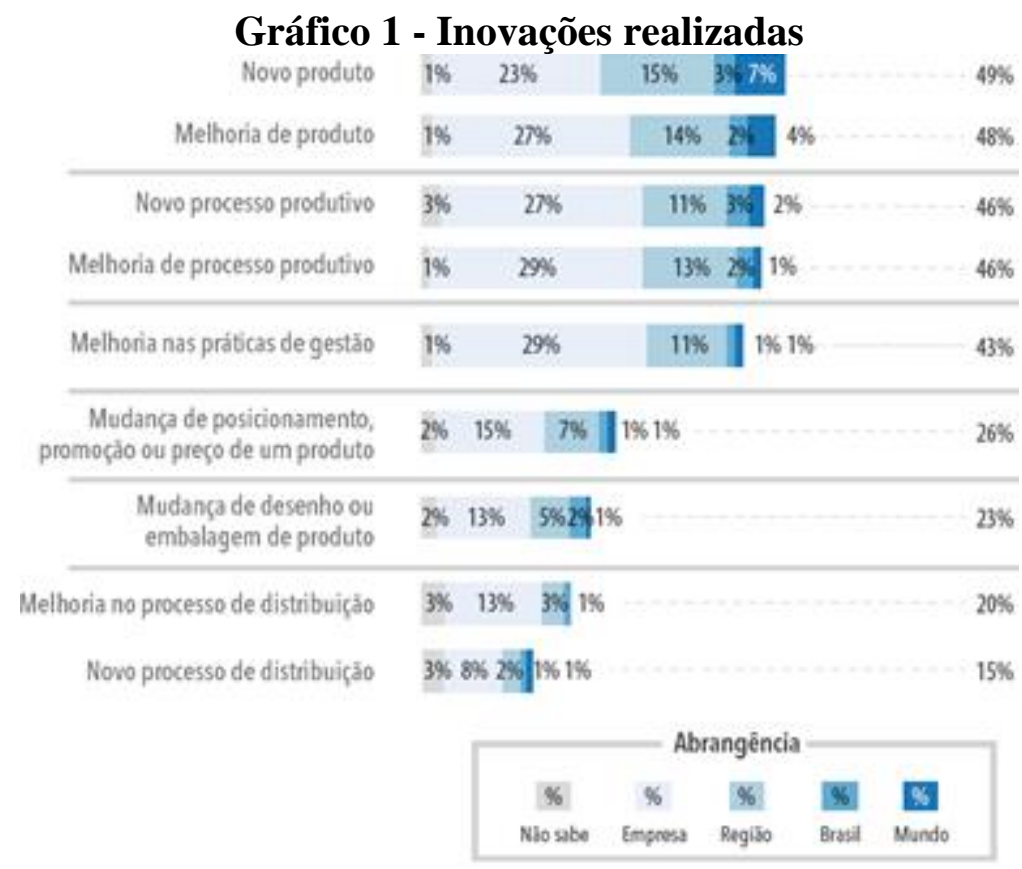

Fonte: Bússola da Inovação (2016)

A geração de resultados efetivos da gestão da inovação demanda algumas práticas de apoio. Conforme o Gráfico 2, entre as práticas não utilizadas e pouco utilizadas destacam-se o gerenciamento de propriedade intelectual $(65 \%)$ e a aquisição externa de tecnologia (67\%). Esses resultados podem estar relacionados à menor maturidade de inovação das indústrias, uma vez que esse tipo de prática exige um maior nível de desenvolvimento.

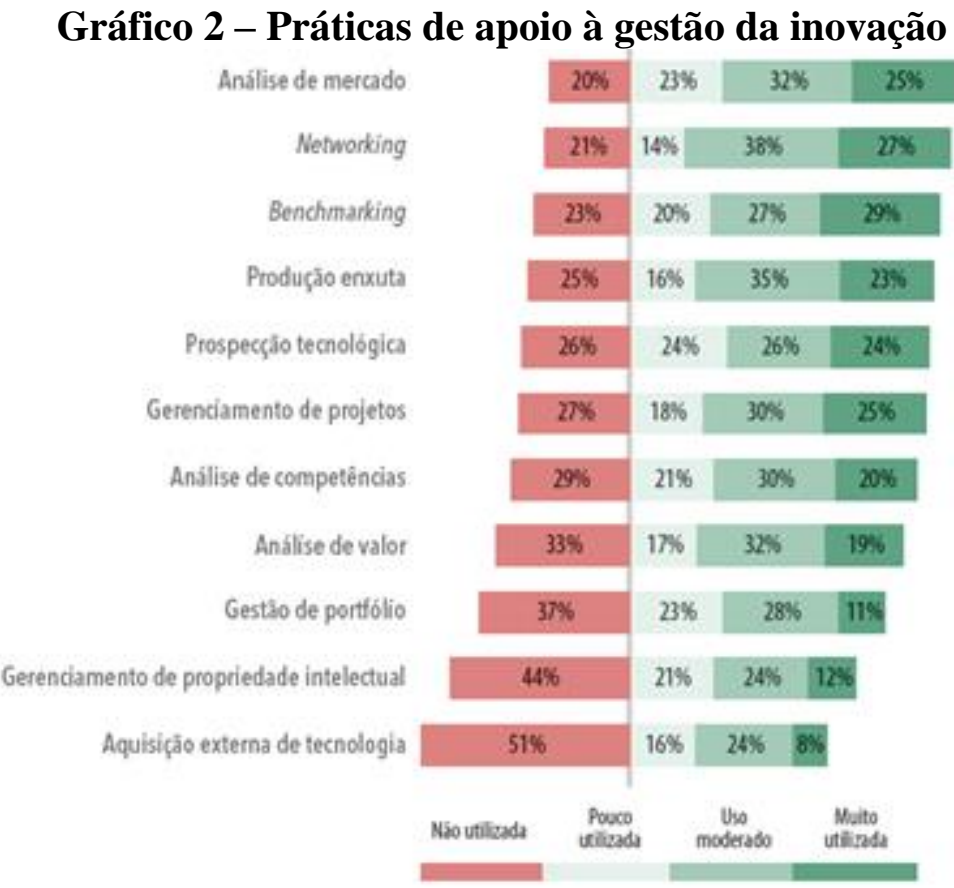

Fonte: Bússola da Inovação (2016)

O clássico problema de maturidade tecnológica está associado ao acúmulo de capacidade tecnológica o suficiente para tornar-se competitivo no mercado. Tal acumulação se dá em uma sequência, que para indústrias em economias emergentes, como é o caso das 
empresas estudadas nesse trabalho, tende a ser do tipo "produção-investimento-inovação" (BELL ET AL., 1984; DAHLMAN ET AL., 1987).

Melo et al. (2020) analisaram a relação entre o uso de instrumentos de políticas públicas de inovação e a gestão da inovação e concluíram que o acesso aos instrumentos contribuiu para o surgimento de comportamentos inovadores, contudo, não foi suficiente para promover uma gestão da inovação continua. Para Matos (2013), a presença de um líder que seja catalisador da inovação dentro da organização e a capacidade estratégica das empresas em estabelecer vínculos externos com outros agentes, principalmente universidades, são atitudes fundamentais para impulsionar a gestão da inovação.

\section{MÉTODO}

O estudo é classificado como quantitativo, de caráter descritivo, no qual foi realizado aplicação de questionários com ofertantes e demandantes de tecnologia no estado do Ceará. Para atingir o objetivo deste trabalho, fez-se necessária a construção de dois instrumentos de pesquisa diferentes: um para coletar dados referentes às demandas da indústria e outro para as ofertas tecnológicas, com 13 e 14 questões, respectivamente.

No caso da demanda, buscou-se levantar de um a dois problemas ou oportunidades existentes na empresa que pudessem ser solucionados por meio do desenvolvimento de uma tecnologia, os quais o respondente deveria descrever e apontar o nível de gravidade, urgência e tendência dos problemas ou oportunidades. O levantamento da gravidade, urgência e tendência foi com o objetivo da aplicação da técnica de priorização de problemas GUT (KEPNER; TREGOE, 1981) como uma ferramenta que pode ser utilizada na solução de problemas por ser capaz de priorizá-los permitindo diversas alternativas de ação. As demais questões, objetivas, visavam levantar a disposição em colaborar, investir e adquirir tecnologias da indústria 4.0 que pudessem solucionar seus problemas ou aproveitar oportunidades.

O questionário aplicado aos ofertantes de tecnologia buscou compreender a tecnologia da instituição, bem como a sua aplicação e a sua proposta de valor para o setor industrial. As questões objetivas visavam medir o nível de maturidade da tecnologia, e também levantar a disposição em colaborar com uma empresa interessada em investir na tecnologia para desenvolvê-la.

Os questionários foram aplicados de duas formas: presencialmente ou online. As respostas presenciais foram coletadas por meio de reuniões particulares previamente agendadas por telefone na própria empresa dos respondentes, em eventos para a indústria ocorridos na Federação, em reuniões sindicais e em eventos voltados para o ecossistema local de inovação e de startups. Já as respostas coletadas de forma online se deram por meio de uma versão do questionário do Google Forms, plataforma que permite elaboração e aplicação de formulários pela internet. Após o esforço de pesquisa, foram coletados 41 questionários de demanda e 83 questionários de oferta. Os questionários foram tabulados com o auxílio do programa Microsoft Excel.

\section{RESULTADOS}

Analisando as transcrições das respostas dos empresários e gestores questionados, por meio do uso de um gráfico de nuvens de palavras, foi possível perceber quais as demandas tecnológicas mais presentes na Indústria. O Gráfico 1 mostra que essas demandas se relacionam principalmente ao processo produtivo (produção, processo) e a busca pelo aumento de sua eficiência. 


\section{Gráfico 1 - Nuvem de Palavras das demandas tecnológicas}

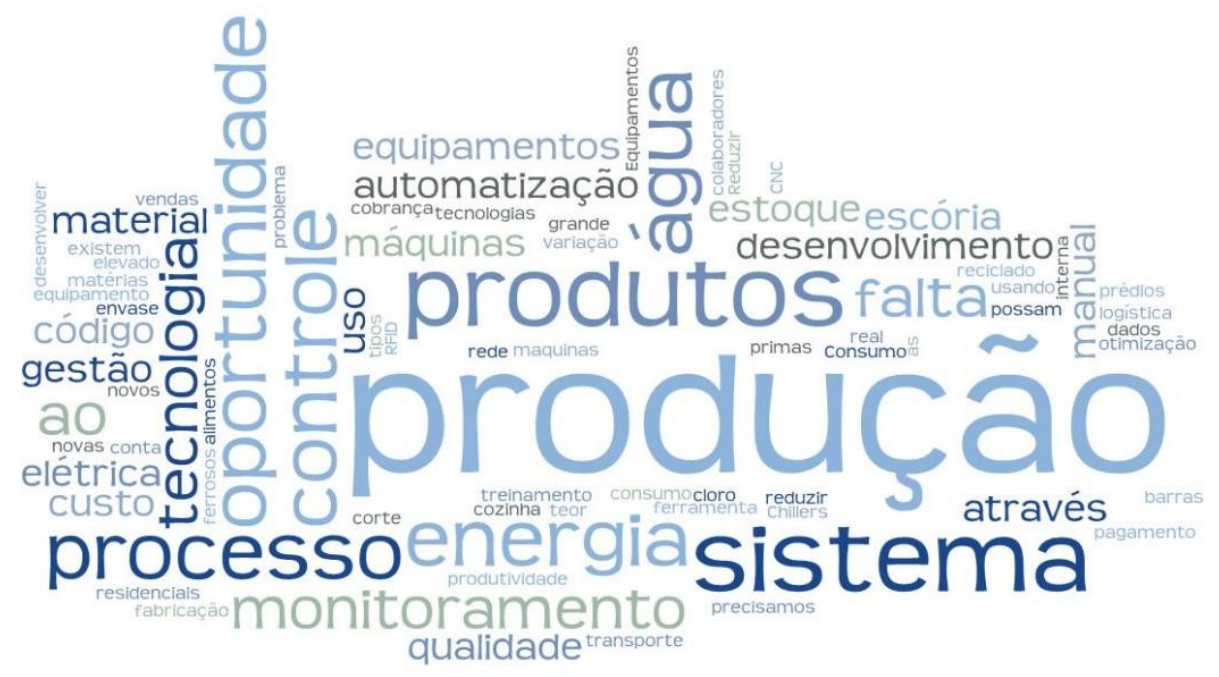

Fonte: elaborado pelos autores

Percebe-se que a maior parte das demandas reveladas estão ainda na categoria das tecnologias básicas e específicas, juntas com mais de $78 \%$ das demandas identificadas nesta pesquisa. Contudo, as tecnologias que de alguma forma se relacionem com aquelas ditas da indústria 4.0 se mostram em $20,29 \%$ dos casos nesta pesquisa e demonstram que de alguma forma as indústrias cearenses já mostram certa preocupação em se posicionar mais próximas da fronteira tecnológica internacional.

\begin{tabular}{c|c|c} 
Quadro 2- Grupos das Demandas Tecnológicas Identificadas \\
\hline \multicolumn{3}{c}{ Grupos de Demandas Tecnológicas (\%) } \\
\hline Tecnologias Básicas & $\begin{array}{c}\text { Tecnologias } \\
\text { Específicas }\end{array}$ & $\begin{array}{c}\text { Tecnologias Tangentes } \\
\text { à Indústria 4.0 }\end{array}$ \\
\hline $42,03 \%$ & $37,68 \%$ & $20,29 \%$ \\
\hline
\end{tabular}

Fonte: Própria pesquisa

Associado à identificação de demandas tecnológicas é preciso revelar o quanto de fato as indústrias cearenses estão necessitando dessas soluções tecnológicas, o que se realizou, considerando a Gravidade do problema que a solução resolve, a urgência com que esse problema precisa ser resolvido pela tecnologia e qual a tendência do quadro ficar mais agudo e mais necessário e urgente no futuro (quadro 3).

Dessa forma, pode-se perceber que as demandas representam problemas graves, uma vez que $76,8 \%$ das demandas identificadas foram classificadas, pelos respondentes da pesquisa, como grave, muito grave e gravíssimo, revelando que precisam ser de fato buscados instrumentos que possam atendê-las para garantir os níveis requisitados de funcionamento e competitividade das indústrias cearenses consultadas.

Percentuais semelhantes foram encontrados para a urgência $(76,8 \%)$ e tendência $(80,1 \%)$ que reforça a importância das demandas identificadas na pesquisa e necessidade de construir políticas de reunião de ofertas com essas demandas tão graves, urgentes e que tenderão a ficar mais ainda necessárias no futuro. 
Quadro 3 - Necessidades Tecnológicas (GUT)

\begin{tabular}{|c|c|c|c|c|c|c|}
\hline Necessidade & \multicolumn{6}{|c|}{ Níveis } \\
\hline \multirow[t]{2}{*}{ Gravidade } & $\begin{array}{c}\text { Não Sabe ou } \\
\text { não } \\
\text { Respondeu }\end{array}$ & Pouco Grave & $\begin{array}{c}\text { Medianamen } \\
\text { te Grave }\end{array}$ & Grave & Muito Grave & Gravíssimo \\
\hline & $14,6 \%$ & $1,2 \%$ & $7,3 \%$ & $37,8 \%$ & $25,6 \%$ & $13,4 \%$ \\
\hline \multirow[t]{2}{*}{ Urgência } & $\begin{array}{c}\text { Não Sabe ou } \\
\text { não } \\
\text { Respondeu }\end{array}$ & $\begin{array}{l}\text { Pouco } \\
\text { Urgente }\end{array}$ & $\begin{array}{l}\text { Medianamen } \\
\text { te Urgente }\end{array}$ & Urgente & $\begin{array}{l}\text { Muito } \\
\text { Urgente }\end{array}$ & Urgentíssimo \\
\hline & $14,6 \%$ & $0,0 \%$ & $8,5 \%$ & $29,3 \%$ & $32,9 \%$ & $14,6 \%$ \\
\hline \multirow[t]{2}{*}{ Tendência } & $\begin{array}{c}\text { Não Sabe ou } \\
\text { não } \\
\text { Respondeu }\end{array}$ & $\begin{array}{l}\text { Tendência } \\
\text { Baixa }\end{array}$ & $\begin{array}{l}\text { Tendência } \\
\text { Média }\end{array}$ & $\begin{array}{l}\text { Tendência } \\
\text { Forte }\end{array}$ & $\begin{array}{l}\text { Tendência } \\
\text { Muito Forte }\end{array}$ & $\begin{array}{l}\text { Tendência } \\
\text { Fortíssima }\end{array}$ \\
\hline & $14,6 \%$ & $2,4 \%$ & $4,9 \%$ & $26,8 \%$ & $29,3 \%$ & $22,0 \%$ \\
\hline
\end{tabular}

Fonte: Própria pesquisa

\subsection{Caracterização da Demanda}

A amostra dos demandantes de tecnologia (GRÁFICO 1) nessa pesquisa mostrou que a maior parte deles $(33 \%)$ necessitam de uma tecnologia pronta para ação no mercado, outros $(21 \%)$ a requerem em fase de pesquisa, seguidos de (15\%) que necessitam ao menos na fase de prototipagem para dá seguimento ao seu desenvolvimento tecnológico.

\section{Gráfico 1 - Disposição da Indústria a adquirir soluções, por nível de maturidade}

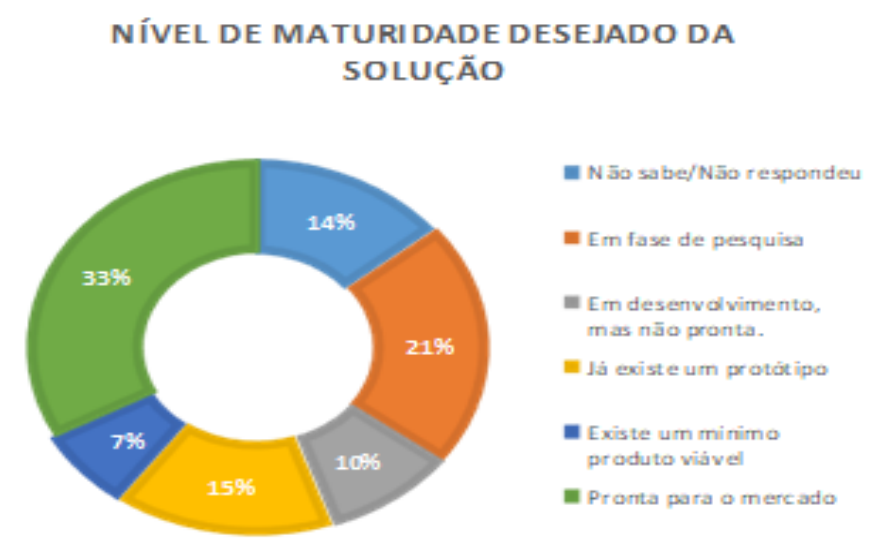

Fonte: Própria Pesquisa

Além disso, houve ainda um número considerável (14\%) que não soube ou não respondeu como gostaria de obter tecnologia demandada, seguido de (10\%) que a requerem em fase de desenvolvimento e apenas (7\%) que necessitam ao menos de algo viável tecnologicamente para resolução de problemas.

Disso pode-se inferir, conforme apontam Chiarello (2009) e Arbix e Miranda (2015), que o setor que promove a geração de conhecimento no Brasil é representado em sua maioria por instituições públicas, enquanto que o setor privado é responsável por absorver esse conhecimento e os converter em bens e serviços.

No entanto, ainda há problemas quanto à essa absorção de conhecimento por parte do setor privado. A maior parte dessas empresas, demandantes de soluções tecnológicas, necessitam da tecnologia pronta para resolução dos seus problemas. Isso pode estar relacionado à baixa capacidade inovativa e baixos níveis de capacidades absortiva, pois essas empresas não conseguem se apropriar de uma tecnologia em estágio de desenvolvimento e 
avançar em suas próximas etapas de desenvolvimento tecnológico. Ao exigirem uma tecnologia que resolva prontamente seus problemas, essas empresas dificultam à colaboração com os ofertantes de tecnologia.

Dessa forma, investigou-se quais as fontes de tecnologia os demandantes estariam mais dispostos a adquirir, a tabela 5 exemplifica esse resultado.

Tabela 5 - Fontes de Tecnologias e Disposição a Adquirir

\begin{tabular}{c|c|c|c|c|c}
\hline Fontes & $\begin{array}{c}\text { Sem } \\
\text { disposiçã } \\
\text { o }\end{array}$ & $\begin{array}{c}\text { Pouco } \\
\text { disposto }\end{array}$ & Disposto & $\begin{array}{c}\text { Muito } \\
\text { disposto }\end{array}$ & $\begin{array}{c}\text { Totalmen } \\
\text { te } \\
\text { disposto }\end{array}$ \\
\hline Start-ups & $9,8 \%$ & $19,5 \%$ & $26,8 \%$ & $29,3 \%$ & $14,6 \%$ \\
\hline ICT's & $9,8 \%$ & $9,8 \%$ & $36,6 \%$ & $24,4 \%$ & $19,5 \%$ \\
\hline $\begin{array}{c}\text { Cursos } \\
\text { externos }\end{array}$ & $9,8 \%$ & $7,3 \%$ & $24,4 \%$ & $39,0 \%$ & $19,5 \%$ \\
\hline $\begin{array}{c}\text { Consultori } \\
\text { a }\end{array}$ & $12,2 \%$ & $14,6 \%$ & $12,2 \%$ & $43,9 \%$ & $17,1 \%$ \\
\hline Outras & $58,5 \%$ & $2,4 \%$ & $17,1 \%$ & $7,3 \%$ & $12,2 \%$ \\
\hline
\end{tabular}

Fonte: Própria pesquisa

Somando-se os percentuais de muito disposto e totalmente disposto, temos o potencial real de disposição do demandante adquirir tecnologia em uma determinada fonte.Assim, de acordo com a tabela 5, a fonte que possui maior potencial em fornecer conhecimento ou tecnologia para os demandantes da amostra são na ordem: consultoria com 61\%; cursos externos com 58,5\%; e ICT e Start-up ambos com 43,9\%. Outras fontes de obtenção tecnológica não se demonstram confiáveis pelos demandantes.

Isso remete o que Garcia, Rapini e Cário (2018) argumentam, onde as demandas tecnológicas das firmas são mais restritas a características estruturais da dinâmica tecnológica periférica quando percebemos a maior incidência em consultorias e curso externos, contudo como apontam Veloso Filho e Nogueira (2016) a RETEC pode contribuir de maneira relevante com a distribuição dessa demanda para empresas que realmente consigam responder de forma assertiva o que essa sendo solicitado como é o caso das ICT e Start-up que já apresentam números razoável de potencial de disposição como fontes tecnológicas.

No que remete as formas em que os empresários estão dispostos a colaborar (GRÁFICO 2) com o desenvolvimento tecnológico, percebe-se um maior potencial em realizar testes com 73\%; informar requisitos com 68\%; Codesenvolver com 65\% seguido de ser piloto para tecnologia com $63 \%$. 


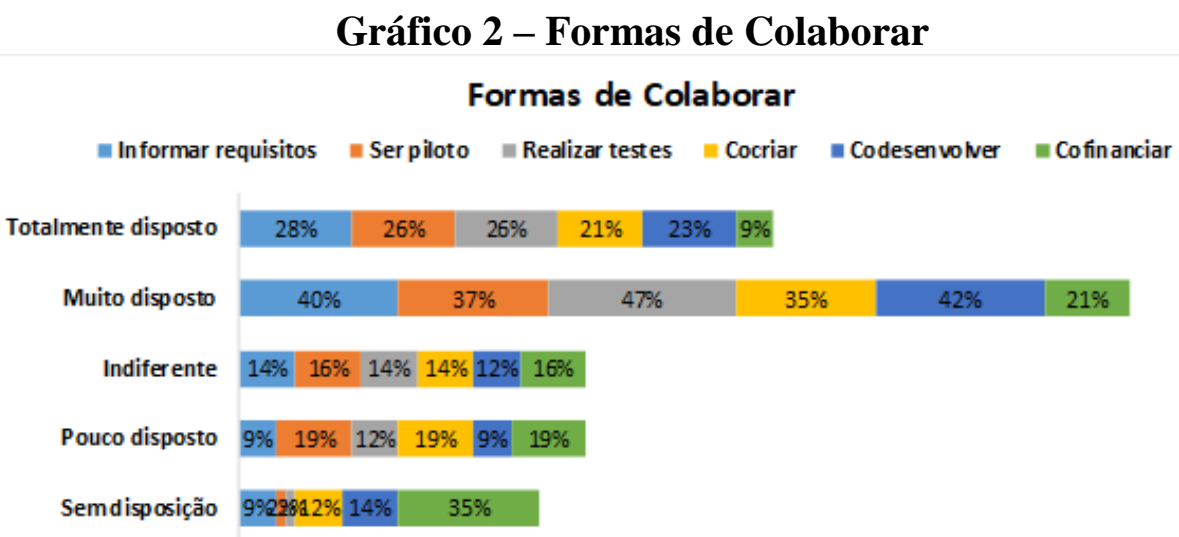

Em contrapartida, a forma de colaborar apontada como mais indisposta pelos empresários é o financiamento, que atinge $54 \%$ do potencial, somando-se pouco disposto e sem disposição. Dessa forma, os financiamentos em inovação, devido seus altos riscos, partem em sua maioria do estado, o que pode justificar a indisposição apresentada (MAZZUCATO, 2014).

Isso está de acordo com o que relatam Lin e Chang (2009) e Viera, Avellar e Veríssimo (2014), que em economias emergentes, as instituições governamentais são os verdadeiros pilares para proteção e investimento nas empresas que, por sua vez, são basilares para o crescimento econômico desses países.

A despeito da falta de investimento do setor privado para o desenvolvimento de produtos inovadores, foi levantado junto aos demandantes seus interesses de investir em determinados segmentos pelo nível de maturidade que se apresenta a tecnologia, conforme tabela

Tabela 6 - Interesse relacionado ao nível de maturidade das tecnologias da Indústria 4.0

\begin{tabular}{l|c|c|c|c|c|c}
\hline $\begin{array}{c}\text { Interesse a } \\
\text { Investir pela } \\
\begin{array}{c}\text { Maturidade } \\
\text { Tecnológica }\end{array}\end{array}$ & $\begin{array}{c}\text { Não sabem } \\
\text { ou não } \\
\text { respondera } \\
\text { m }\end{array}$ & $\begin{array}{c}\text { Solução } \\
\text { tecnologi } \\
\text { a ainda } \\
\text { em fase } \\
\text { de } \\
\text { pesquisa }\end{array}$ & $\begin{array}{c}\text { Solução } \\
\text { tecnológica } \\
\text { já em } \\
\text { desenvolvim } \\
\text { ento, mas } \\
\text { não pronta. }\end{array}$ & $\begin{array}{c}\text { Já existe } \\
\text { um } \\
\text { protótipo } \\
\text { da } \\
\text { solução } \\
\text { tecnológi } \\
\text { ca }\end{array}$ & $\begin{array}{c}\text { Existe } \\
\text { um } \\
\text { mínimo } \\
\text { produto } \\
\text { viável }\end{array}$ & $\begin{array}{c}\text { Solução } \\
\text { tecnológi } \\
\text { ca já } \\
\text { pronta } \\
\text { para o } \\
\text { mercado }\end{array}$ \\
\hline Big Data & $29,3 \%$ & $17,1 \%$ & $7,3 \%$ & $17,1 \%$ & $4,9 \%$ & $24,4 \%$ \\
\hline Robótica & $26,8 \%$ & $17,1 \%$ & $12,2 \%$ & $7,3 \%$ & $17,1 \%$ & $19,5 \%$ \\
\hline $\begin{array}{l}\text { Simulação } \\
\text { Computacional }\end{array}$ & $29,3 \%$ & $19,5 \%$ & $9,8 \%$ & $14,6 \%$ & $12,2 \%$ & $14,6 \%$ \\
\hline $\begin{array}{l}\text { Sistema } \\
\text { Integração }\end{array}$ & $36,6 \%$ & $22,0 \%$ & $4,9 \%$ & $12,2 \%$ & $12,2 \%$ & $12,2 \%$ \\
\hline $\begin{array}{l}\text { Internet das } \\
\text { Coisas }\end{array}$ & $24,4 \%$ & $29,3 \%$ & $7,3 \%$ & $14,6 \%$ & $14,6 \%$ & $9,8 \%$ \\
\hline $\begin{array}{l}\text { Segurança } \\
\text { Cibernética }\end{array}$ & $31,7 \%$ & $14,6 \%$ & $7,3 \%$ & $12,2 \%$ & $12,2 \%$ & $22,0 \%$ \\
\hline
\end{tabular}




\begin{tabular}{l|c|c|c|c|c|c}
$\begin{array}{l}\text { Computação } \\
\text { nas Nuvens }\end{array}$ & $19,5 \%$ & $24,4 \%$ & $9,8 \%$ & $12,2 \%$ & $14,6 \%$ & $19,5 \%$ \\
\hline $\begin{array}{l}\text { Manufatura } \\
\text { Aditiva }\end{array}$ & $36,6 \%$ & $24,4 \%$ & $4,9 \%$ & $17,1 \%$ & $9,8 \%$ & $7,3 \%$ \\
\hline $\begin{array}{l}\text { Realidade } \\
\text { Aumentada }\end{array}$ & $41,5 \%$ & $26,8 \%$ & $2,4 \%$ & $9,8 \%$ & $9,8 \%$ & $9,8 \%$ \\
\hline
\end{tabular}

Fonte: Própria pesquisa

Os altos percentuais na opção não sabem ou não responderam, verificados em todos os segmentos, reforçam a indisposição do setor privado em investir em inovação (CHIARELLO, 2009; ARBIX; MIRANDA, 2015). Contudo, nota-se que, quando o nível de maturidade tecnológica aponta um mínimo de produto viável ou a tecnologia já está pronta para o mercado, a disposição de investimento pelos empresários aumenta. Isso se deve à diminuição do nível de incerteza de viabilidade sobre o produto inovador. O setor privado possui interesse em investir em etapas posteriores de desenvolvimento tecnológica, de modo que o primeiro incentivo deve-se partir do estado para que ocorra a diminuição do risco envolvido (MAZZUCATO, 2014).

De acordo com a tabela 6 , quando o potencial de nível de maturidade tecnológica aponta um mínimo de produto viável masa tecnologia já está pronta para o mercado, os segmentos mais propícios de receberem investimentos são: robótica (36,6\%); segurança cibernética $(34,2 \%)$ e computação nas nuvens $(34,1 \%)$.

Já com relação ao nível de interesse em investir, percebe-se que uma média de $15 \%$ das demandantes tem muito interesse em investir nessas tecnologias como um todo. Mais especificamente, Cloud Computing é a tecnologia que possui maior quantidade de empresas (20\%) com muito interesse em investir. Por outro lado, juntamente com Realidade Aumentada, são as tecnologias com maior número de empresas que conhecem, mas não possuem interesse em investir (40\%).

Se forem consideradas as médias dos níveis de interesse, considerando todas as tecnologias, percebe-se que a maioria das empresas, embora conheçam as tecnologias, não possuem interesse em investir (Tabela 7).

Tabela 7 - Média do nível de interesse das indústrias em investir em tecnologias da Indústria 4.0.

\begin{tabular}{l|c}
\hline \multicolumn{1}{c|}{ Nível de Interesse } & Média \\
\hline Não conheço e não tenho interesse em investir & $16 \%$ \\
\hline Conheço, mas não tenho interesse em investir & $29 \%$ \\
\hline Conheço, e tenho pouco interesse em investir & $19 \%$ \\
\hline Conheço, e tenho interesse mediano em investir & $21 \%$ \\
\hline Conheço, e tenho muito interesse em investir & $15 \%$ \\
\hline Conheço, e investiria com certeza & $0 \%$ \\
\hline
\end{tabular}

Fonte: Dados da pesquisa.

\subsection{Caracterização da Oferta}

Por parte das ofertas tecnológicas, a oferta se caracteriza (GRÁFIGO 3) em seu maior volume em produtos funcionando de forma bem sucedida em ambiente real com (33\%) e em fase de protótipo com operação bem sucedida no ambiente real com (23\%). 
Gráfico 1 - Estágios em que as tecnologias ofertadas se encontram

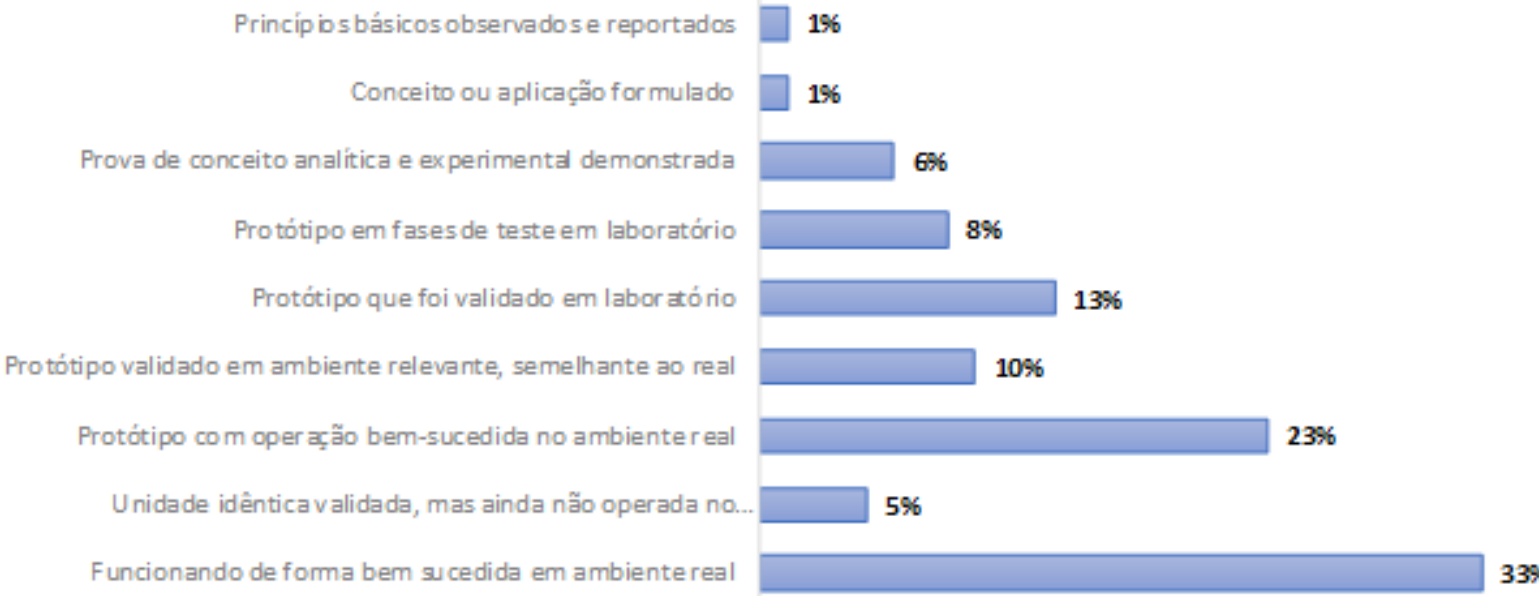

Fonte: Própria Pesquisa

O que ressalta o papel importante que o estado possui no desenvolvimento local de produtos inovadores, visto que a origem desse investimento inicial parte do estado (CHIARELLO, 2009; MAZZUCATO, 2014).

Entretanto, as empresas ofertantes apoiam a colaboração das empresas demandantes no desenvolvimento tecnológico, como pode ser percebido na tabela 8.

Tabela 8 - Relevância em colaborar com empresas para o desenvolvimento da tecnologia

\begin{tabular}{|l|c|c|c|c|c}
\hline \multicolumn{1}{c|}{ Fontes } & $\begin{array}{c}\text { Não é } \\
\text { Relevante }\end{array}$ & $\begin{array}{c}\text { Pouco } \\
\text { Relevante }\end{array}$ & Relevante & $\begin{array}{c}\text { Muito } \\
\text { Relevante }\end{array}$ & $\begin{array}{c}\text { Extremamente } \\
\text { Relevante }\end{array}$ \\
\hline $\begin{array}{l}\text { Colaboração no } \\
\text { desenvolvimento } \\
\text { de produtos }\end{array}$ & $0 \%$ & $0 \%$ & $21 \%$ & $23,4 \%$ & $55,6 \%$ \\
\hline
\end{tabular}

Fonte: Própria pesquisa

O potencial de percepção relevante sobre o codesenvolvimento de produtos por parte da amostra de fornecedores é de $79 \%$, um número muito elevado, o que pode ter uma grande contribuição por meio da RETEC como argumentam Veloso Filho e Nogueira (2016) sobre o papel que desempenha essa rede, buscando aproximar as universidades, centros de pesquisas e empresas.

Segue-se a mesma tendência de potencial de relevância quanto à transferência tecnológica do produto para o mercado. Cerca de $83 \%$ da amostra dos ofertantes considera relevante a colaboração dos demandantes na fase de transferência tecnológica, conforme apontado na tabela 8,o que permite inferir ser essa fase um passo importante de se atingir o objetivo proposto em um mercado competitivo.

Tabela 8 - Relevância em colaborar com empresas para a transferência tecnológica do produto para o mercado

\begin{tabular}{l|c|c|c|c|c}
\hline \multicolumn{1}{c|}{ Fontes } & $\begin{array}{c}\text { Não é } \\
\text { Relevante }\end{array}$ & $\begin{array}{c}\text { Pouco } \\
\text { Relevante }\end{array}$ & Relevante & $\begin{array}{c}\text { Muito } \\
\text { Relevante }\end{array}$ & $\begin{array}{c}\text { Extremamente } \\
\text { Relevante }\end{array}$ \\
\hline $\begin{array}{l}\text { Colaboração no } \\
\text { desenvolvimento de } \\
\text { produtos }\end{array}$ & $0 \%$ & $1,2 \%$ & $16,1 \%$ & $29,6 \%$ & $53,1 \%$ \\
\hline
\end{tabular}

Fonte: Própria pesquisa 
Desse modo, a transferência tecnológica, segundo Braga Jr., Pio e Antunes (2009), torna-se uma fase estratégica para o desenvolvimento das empresas levando-as a possuir uma orientação de produção voltada ao mercado, assim o codesenvolvimento dos produtos é encarado como altamente relevante, visto que a produção já sai o mais perto possível do que é esperado pelo próprio cliente que colabora no desenvolvimento.

De acordo com a tabela 9, denota-se que os ofertantes estão dispostos a se relacionar na colaboração em todas as formas levantadas, cabe destacar as formas de relacionamento receber investimento, licenciamento e Know-How, com 79,01\%; 70,37\% e 60,49\%, respectivamente.

Tabela 9 - Formas de relacionamento com o Setor Produtivo

\begin{tabular}{l|c|c|c|c|c}
\hline \multicolumn{1}{c|}{ Fontes } & $\begin{array}{c}\text { Sem } \\
\text { disposição }\end{array}$ & $\begin{array}{c}\text { Pouco } \\
\text { disposto }\end{array}$ & Disposto & $\begin{array}{c}\text { Muito } \\
\text { disposto }\end{array}$ & $\begin{array}{c}\text { Totalmente } \\
\text { disposto }\end{array}$ \\
\hline Know-how & $1,23 \%$ & $1,23 \%$ & $8,64 \%$ & $28,40 \%$ & $60,49 \%$ \\
\hline Investimento & $1,23 \%$ & $0 \%$ & $1,23 \%$ & $18,52 \%$ & $79,01 \%$ \\
\hline Licenciamento & $1,23 \%$ & $1,23 \%$ & $2,47 \%$ & $24,69 \%$ & $70,37 \%$ \\
\hline Spin-off & $4,94 \%$ & $4,94 \%$ & $13,58 \%$ & $28,40 \%$ & $48,15 \%$ \\
\hline
\end{tabular}

Fonte: Própria pesquisa

Assim, iniciativas como a RETEC, REDINIT e NUTEC podem somar nesse relacionamento criando um ambiente inovador aproximando empresas demandantes das instituições ofertantes, reforçando-se o papel do estado do desenvolvimento tecnológico da região (MAZZUCATO, 2014).

\section{CONSIDERAÇÕES FINAIS}

Essa pesquisa buscou levantar o potencial de inovação do estado do Ceará, ao elencar a disponibilidade de ofertas e demandas tecnológicas do estado. Percebe-se que existem grandes demandas no cenário industrial cearense e que os empresários entendem a necessidade e desejam uma maior conexão com os desenvolvedores de tecnologia e ICT's. Dentre os principais problemas apontados pelas indústrias pesquisadas, encontram-se melhoria da eficiência energética e do uso da água, bem como automatização de parte ou de todo o processo produtivo.

Foi visto que a maioria dos ofertantes já possui produto pronto para o mercado, enquanto os demandantes têm maior necessidade justamente por esses produtos prontos. Seguido dos produtos acabados, a pesquisa demonstrou que as indústrias também possuem muito interesse em colaborar no desenvolvimento de tecnologias que ainda estão em fase de pesquisa, retratando que parte dos seus problemas não serão resolvidos com um produto padrão - deve ser individualizado.

Entretanto, o cruzamento dos dados também deixou claro que as startups e ICT's têm um interesse mais contundente em firmar parcerias para desenvolver tecnologias do que as indústrias, especialmente quando se trata de cofinanciamentos e realização de testes de produtos no ambiente da indústria.

Em paralelo, observou-se que a indústria, de maneira geral, não tem um conhecimento amplo das tecnologias da Indústria 4.0, principalmente no que se refere à Manufatura Aditiva e Sistemas de Integração Vertical e Horizontal. Por outro lado, existe oferta de tecnologias da Indústria 4.0 (especialmente robótica, big data, internet das coisas e manufatura aditiva) e as empresas cearenses podem beneficiarem-se delas. Assim, faz-se necessário um maior esforço 
de divulgação dessas tecnologias, visto que existem demandantes que sequer conhecem as tecnologias mais avançadas que poderiam solucionar seu problema.

As conclusões que esta pesquisa nos leva a ter, com respeito ao levantamento e análise das demandas tecnológicas das indústrias cearenses, podem ser relacionados com: i) os tipos de demandas tecnológicas; ii) as fontes externas de onde estas demandas poderiam vir; iii) as formas como a colaboração pode ser usada no atendimento destas demandas e iv) como as demandas se relacionam com as tecnologias da chamada indústria 4.0.

Por fim, as limitações da pesquisa dizem respeito à quantidade de empresas acessadas, o que limita a generalização dos resultados para além do universo investigado. É possível também que a pesquisa de caráter quantitativo não exponha determinadas demandas das empresas. Assim, sugere-se que uma pesquisa qualitativa possa abordar temáticas não contempladas por esta pesquisa, buscando aprofundar nas necessidades e demandas da indústria cearense, bem como as ofertas tecnológicas disponíveis para solucionar os gargalos produtivos. 


\section{REFERÊNCIAS}

ARBIX, G.; MIRANDA, Z. Inovação em tempos difíceis. Plural, v. 22, n. 2, 2015.

BALESTRIN, Alsones; VERSCHOORE, Jorge Renato; REYES JUNIOR, Edgar. O campo de estudo sobre redes de cooperação interorganizacional no Brasil. RAC-Revista de Administração Contemporânea, v. 14, n. 3, 2010.

BELL, M.; ROSS-LARSON, B.; WESTPHAL, L. E., Assessing the Performance of Infant Industries, Washington, DC: The World Bank, 1984.

BRAGA, JR., E.; PIO, M.; ANTUNES, A. O processo de transferência de tecnologia na indústria têxtil. Journal of technology management \& innovation, v. 4, n. 1, p. 125-133, 2009.

BRESCHI, S.; MALERBA, F. Clusters. Networks and Innovation, Oxford University Press, 2005.

BÚSSOLA DA INOVAÇÃO. Perfil de Inovação Industrial. 2016. Disponível em: https: //www1.sfiec.org.br/observatorio-da-industria/programa/92188/bussola-da-inovacao. Acesso em: 08 de março de 2019.

CHIARELLO, M. As plataformas tecnológicas e a promoção de parcerias para a inovação. Parcerias estratégicas, v. 5, n. 8, p. 93-102, 2009.

CHOI, H. Technology-push and demand-pull factors in emerging sectors: evidence from the electric vehicle market, Industry and Innovation, n. 25, v. 7, pp. 655-674, DOI: 10.1080/13662716.2017.1346502, 2017.

DAHLMAN, C.; ROSS-LARSON, B.; WESTPHAL, L. E., "Managing Technological Development: Lessons from the Newly Industrializing Countries", in World Development, v.15, n.6, p.759- 75, 1987.

FIEC. CEI - Centro de Excelência em Inovação. 2020a. Disponível em: https://www1.sfiec.org.br/para-industria/86852/centro-de-excelencia-em-inovacao. Acesso em 08 de abril de 2020.

FIEC. Programa para Desenvolvimento da Indústria. 2020b. Disponível em: https://www1.sfiec.org.br/observatorio-da-industria/programas. Acesso em 08 de abril de 2020.

FREIRE, Carlos Torres; MARUYAMA, Felipe Massami; POLLI, Marco. Inovação e empreendedorismo: políticas públicas e ações privadas. Novos estudos, n. 109, p. 50-76, 2017.

GARCIA, R.; RAPINI, M.; CÁRIO, S. Experiências de interação universidade-empresa no Brasil. Belo Horizonte: UFMG, Ed: CEDEPLAR, 2018. 
GOVERNO DO CEARÁ. Ceará e Fiocruz fecham parceria para desenvolver o Polo Industrial e Tecnológico da Saúde. 2017. Disponível em: https://www.ceara.gov.br/2017/08/30/ceara-e-fiocruz-fecham-parceria-para-desenvolver-opolo-industrial-e-tecnologico-da-saude/. Acesso em 08 de março de 2019.

IRELAND, R.; DUANE, W.; JUSTIN, W. Strategic entrepreneurship: Creating competitive advantage through streams of innovation. Business horizons, v. 50, n. 1, p. 49-59, 2007.

KETCHEN JR.; DAVID, J.; IRELAND, R.; DUANE, S.; CHARLES, C. Strategic entrepreneurship, collaborative innovation, and wealth creation. Strategic entrepreneurship journal, v. 1, n. 3-4, pp. 371-385, 2007.

KIM, L. Imitation to innovation: The dynamics of Korea's technological learning. Harvard Business Press, 1997.

LASI, Heiner et al. Industry 4.0. Business \& information systems engineering, v. 6, n. 4, p. 239-242, 2014.

LIN, J.; CHANG, H. J. Should Industrial Policy in developing countries conform to comparative advantage or defy it? A debate between Justin Lin and Ha-Joon Chang. Development policy review, v. 27, n. 5, pp. 483-502, 2009.

LOURAL, M. S. Investimentos industriais no Brasil: uma análise do período 1999-2013. Tese (Doutorado)-Universidade Estadual de Campinas, Instituto de Economia, Campinas, São Paulo, 2016. 173p.

LUKAC, D. The fourth ICT-based industrial revolution" Industry 4.0"??? HMI and the case of CAE/CAD innovation with EPLAN P8, in: 2015 23rd Telecommunications Forum Telfor TELFOR, IEEE, pp. 835-838, 2015.

MATOS, Paulo Marcelo Albuquerque. Análise do processo de gestão da inovação na construção civil: um modelo para o Ceará. 2013. 188 f. Dissertação (Mestrado) Universidade Federal do Ceará, Faculdade de Economia, Administração, Atuária e Contabilidade, Programa de Pós-Graduação em Administração e Controladoria, Fortaleza, 2013.

MAZZUCATO, M. O Estado Empreendedor: desmascarando o mito do setor público vs. setor privado. Portfolio-Penguin, 2014.

NUTEC. Serviços. 2020. Disponível em: https://www.nutec.ce.gov.br/servicos/. Acesso em 08 de abril de 2020.

POSADA, J.; TORO, C.; BARANDIARAN, I.; OYARZUN, D.; STRICKER, D.; DE AMICIS, R.; VALLARINO, I. Visual computing as a key enabling technology for industrie 4.0 and industrial internet. IEEE computer graphics and applications, v. 35, n. 2, pp. 26-40, 2015.

REDENIT-CE. A rede. 2020. Disponível em: http://www.redenitce.com.br/\#story. Acesso em 08 de abril de 2020. 
ROBLEK, V.; MEŠKO, M.; KRAPEŽ, A. A complex view of industry 4.0. Sage Open, v. 6, n. 2, 2158244016653987, 2016.

SETHI, A.P.S.; AHUJA, I.P.S.; SINGLA, A. Shifts Between Technology Push and Market Pull Strategies for Sustainable Development in Manufacturing Industries. In: Connell J., Agarwal R., Sushil, Dhir S. (eds) Global Value Chains, Flexibility and Sustainability. Flexible Systems Management. Springer, Singapore. https://doi.org/10.1007/978-981-108929-9_21, 2018.

SILVA, Ana Lucia Gonçalves; LAPLANE, Mariano Francisco. Dinâmica recente da indústria brasileira e desenvolvimento competitivo. Economia e Sociedade, v. 3, n. 1, p. 82-98, 1994.

SINGLA, A.; AHUJA, I.P.S.; SETHI, A.P.S. Technology push and demand pull practices for achieving sustainable development in manufacturing industries. Journal of Manufacturing Technology Management. doi:10.1108/jmtm-07-2017-0138, 2018.

ŚLUSARCZYK, B. Industry 4.0: Are we ready?. Polish Journal of Management Studies, $17,2018$.

THAMES, L.; SCHAEFER, D. Software-defined cloud manufacturing for industry 4.0. Procedia cirp, v. 52, pp. 12-17, 2016.

VASCONCELOS, F. C.; CYRINO, Á. B. Vantagem competitiva: os modelos teóricos atuais ea convergência entre estratégia e teoria organizacional. Revista de Administração de empresas, v. 40, n. 4, p. 20-37, 2000.

VELOSO FILHO, F. A.; NOGUEIRA, J. M. Sistemas de inovação e promoção tecnológica regional e local no Brasil. Interações, v. 8, n. 13, 2016.

VERMULM, Roberto et. al. Políticas para o desenvolvimento da indústria 4.0 no Brasil. 2018.

VAIDYA, Saurabh; AMBAD, Prashant; BHOSLE, Santosh. Industry 4.0-a glimpse. Procedia Manufacturing, v. 20, p. 233-238, 2018.

VIEIRA, F. V.; AVELLAR, A. P.; VERÍSSIMO, M. P. Indústria e crescimento econômico: evidências para países desenvolvidos e em desenvolvimento. Brazilian Journal of Political Economy, v. 34, n. 3, pp. 485-502, 2014. 